\title{
ERRATA: VOLUME 1
}

The editors apologize for the following errors that occurred in Volume 1 of The Bulletin of the International Association for Robin Hood Studies (2017).

- Stephen Knight, "Robin Hood and the Forest Laws," p. 11: "Hannah Bernstein" should read "Hannah Weinstein".

- Steven Basdeo, “A Critical Edition of Little John's Answer to Robin Hood and the Duke of Lancaster (1727)," p. 15: The superscript footnote numbers 7 and 8 in the essay proper should have been combined into one footnote number. 